\title{
Is it still worth it? Applying expectancy-value theory to investigate the intraindividual motivational process of forming intentions to drop out from university
}

\author{
Theresa Schnettler ${ }^{1}$ (D) Julia Bobe ${ }^{2} \cdot$ Anne Scheunemann $^{1} \cdot$ Stefan Fries $^{1} \cdot$ Carola Grunschel $^{3}$
}

Published online: 17 February 2020

(c) The Author(s) 2020

\begin{abstract}
The intraindividual process of study dropout, from forming dropout intention to deregistration, is of motivational nature. Yet typical studies investigate interindividual differences, which do not inform about intraindividual processes. Our study focused on the intraindividual process of forming dropout intention, and applied expectancy-value theory to analyze its motivational underpinnings. To expand research, we considered associations of intraindividual deviations in expectancy, intrinsic value, attainment value, utility value, and cost to intraindividual deviations in dropout intention. A total of 326 undergraduate students of law and mathematics rated motivational variables and dropout intention three times from semester start to the final exam period. Multilevel regression analyses revealed that intraindividual changes in intrinsic value, attainment, and cost, but not in expectancy and utility, related to intraindividual changes in dropout intention. Further, we considered students' demographics as moderators. Only age moderated the association between intrinsic value and dropout intention. Our results stress the crucial role of certain value components, including cost, for emerging dropout intention.
\end{abstract}

Keywords Dropout intention · Expectancy-value theory $\cdot$ University students $\cdot$ Longitudinal study

Internationally, an increasing number of students have been deciding to enter higher education every year (UNESCO Institute for Statistics [UIS], 2018). Along with this, universities strive to fulfill their academic and economic mission (Larsen et al. 2013) by achieving high retention and graduation rates (Berger and Lyon 2005). However, the number of students who leave the higher education system without obtaining a first degree is increasing. Studies report that roughly currently about one out of three students are leaving prior to graduation (e.g., Organization for Economic CoOperation and Development [OECD] 2018). In the STEM disciplines (Science, Technology, Engineering, Mathematics), the dropout rate is even higher, with estimates of 40 to

Theresa Schnettler

theresa.schnettler@uni-muenster.de

1 Department of Psychology, Bielefeld University, P.O. Box 10 01 31, Universitätsstraße 25, 33501 Bielefeld, Germany

2 Psychology Department, Paderborn University, Paderborn, Germany

3 Department of Educational Psychology, University of Münster, Münster, Germany
50 percent (Ulriksen et al. 2010). This development challenges and negatively affects not only the students involved, but also institutions of higher education, and society (Bound and Turner 2011; Schiefele et al. 2007).

Motivation is a key factor for effective studying, and especially academic decision-making (Eccles 2005; Richardson et al. 2012). Previous studies have indicated an overall decrease in motivation over time (cf. Musu-Gillette et al. 2015; Scherrer and Preckel 2019). Such a decrease is associated with a higher intention to drop out from university (cf. Dresel and Grassinger 2013). Most of the contemporary studies were conducted as field research, and addressed questions of interindividual differences to explain dropout phenomena. For instance, students who valued their studies significantly less than their fellow students dropped out of university more often (Schiefele et al. 2007). These findings from the interindividual level, like findings from group statistics (e.g., means or correlations) can only be transferred to the intraindividual level under restrictive conditions (Hamaker 2012; Molenaar 2013). Disregard often leads to inaccurate conclusions (Fisher et al. 2018). For instance, research on success expectations has found that students holding higher success expectation than their 
fellow students (interindividual level) showed better performance (cf. Robbins et al. 2004). However, a closer look at the intraindividual level revealed a reverse effect (Vancouver and Kendall 2006). As deciding to drop out of university can be seen to be an individual process (Heublein et al. 2017), studies focusing on the intraindividual associations between motivation and dropout intention are informative for helping close this research gap.

In the current study, we focused on investigating the association of intraindividual changes in motivation from the perspective of expectancy-value theory (EVT; cf. Eccles et al. 1983; Wigfield et al. 2017) and intraindividual changes in dropout intention over the course of one semester. Thereby, we address current criticism to reestablish and deepen the intraindividual perspective on EVT (Kosovich et al. 2017; Nagengast et al. 2013). Further, we broaden the view, to interindividual demographic variables, which possibly influence the strength of the relationship between motivation and dropout intention.

\section{Research on Study dropout and study dropout intention}

Researchers use several terms to describe dropout phenomena (Hovdhaugen 2009). In our study, we define study dropout from university in accordance with Tinto (1993) as "situations where a student leaves the university study in which (s)he has enrolled before having obtained a formal degree" (Larsen et al. 2013, p. 5). This includes the change of majors, and the permanent leave from the higher education system.

Many theoretical models and studies on study dropout have not investigated direct dropout behavior (cf. Sosu and Pheunpha 2019). Rather, they have focused on the probability to drop out. For instance, some studies from the field of educational economics and machine learning investigated interindividual characteristics, such as age and gender, or institutional and economic characteristics (see Alban and Mauricio 2019 for a review). These studies, as well as studies in the field of psychology (cf. Alarcon and Edwards 2013), inform researchers and university counseling services about certain groups of students who are at risk of dropping out. By addressing time invariant interindividual characteristics, such as personality and gender (cf. Vinciguerra et al. 2019), studies answer the question of whom to address with intervention and counseling services. At the same time, they do not shed light on the question of which of the time varying variables, such as motivation, are related to study dropout. However, this is important to know for intervention or counseling services, or if some variables are especially relevant for the treatment of certain subgroups.
Models that focus on interindividual differences of timevarying variables that influence students' decisions to drop out of university dominate the field of research, and last to the 1970s. The most prominent model derived from the field of sociology is known as the student integration model (Cabrera et al. 1993). It applies Durkheim's (1951) theory of suicide to the academic context (Spady 1971; revised by Tinto 1975). This model describes study dropout as a process in terms of academic and social integration. In line with this theory, study dropout is caused by an interplay of individual characteristics (e.g., family background), commitments toward the academic goal and the institution, and the ongoing process of integration. To date, the model has not been fully put to test empirically, and findings are rather mixed (cf. Braxton et al. 1997; Duque 2014). An alternative model from a psychological perspective applied concepts and variables from the psychological organizational literature (e.g., employee turnover) to explain study dropout (Bean 1982). This theory is nowadays referred to as the student attrition model (Cabrera et al. 1993), stressing the importance of attitudes, the student-environment fit, and external factors, such as family support. Dewberry and Jackson (2018) brought up a more recent theoretical perspective on study dropout. They applied the theory of planned behavior (TPB; Ajzen 1991) to study dropout, and stressed the importance of considering the psychological perspective of students' active choice. By comparing the predictive value of variables of the TPB to variables of the student integration model regarding dropout intention, Dewberry and Jackson (2018) found the variables of TPB (e.g., students' attitudes toward courses and success expectations) to be more accurate predictors. That indicates that variables which target students' attitudes and motivation toward studies are of high relevance for study dropout (Dewberry and Jackson 2018). A limitation of these models and corresponding findings is that they do not explicitly address the intraindividual process itself. Instead, mostly static interindividual differences in different subsets of variables were the in the focus of analyses.

However, inherent in all of these models is the explicit focus on dropout intention as a cognitive representation of decision-making, which is the best proxy for subsequent dropout behavior (Bean 1982; Mashburn 2000). Thus, dropout intention is considered as an early warning sign for study dropout (Brandstätter et al. 2006), and is widely used in recent studies which investigate dropout phenomena (cf. Bäulke et al. 2018; Suhlmann et al. 2018). Practically, investigating the formation of dropout intention at an early stage enables practitioners to design tailor-made counseling services right at the beginning of the decisionmaking process. 


\section{A gradual process of forming dropout intention}

Framing study dropout in models such as Heckhausen's action phase model (cf. Heckhausen and Gollwitzer 1987; Heckhausen and Heckhausen 2018) has considerable potential to inform about the intraindividual intention formation in a finer granularity. Thereby, the motivational nature of intention formation within the decision-making process becomes apparent. The action phase model aims at explaining goal engagement and goal pursuit, and consists of four unique phases, namely predecisional phase, preactional phase, actional phase, and postactional phase. Each phase inherits a special kind of mindset or cognitive orientation (Gollwitzer 1990). In the predecisional phase, individuals engage within a deliberate mindset in goal setting and intention formation, which is of motivational nature. As a result, they arrive at a decision of whether or not to form an intention to pursue their goal. In the preactional phase, individuals engage in action planning, within an implemental mindset (volitional preoccupation; Gollwitzer 1990), focusing on intention implementation. In the acting phase, the mindset is still volitionally preoccupied (Gollwitzer 1990), so "information processing and evaluation are strongly biased in favor of the chosen alternative" (Heckhausen and Heckhausen 2018, p. 7). Lastly, in the postactional phase, individuals focus on "evaluating outcomes and consequences of goal striving" (Gollwitzer 1990, p. 66), within a deliberate mindset which is similar to the mindset of the predecisional phase. Thus far, the postactional phase has received limited empirical attention compared to the other phases (McCrea and Vann 2018). As goal-disengagement counteracts the goal-engagement process (Heckhausen and Heckhausen 2018), framing the dropout process in the action phase model is beneficial for informing about the motivational nature of the phase of forming dropout intention, which we focus on.

Previous studies of Brandstätter et al. (2013) investigated goal-disengagement and action crisis, and linked study dropout explicitly to the action phase model. They pointed out that dropout intentions can be considered as an action crisis that arises when students are engaged in goal pursuit. The action crisis can lead to goal disengagement, and thus study dropout. Theoretically, Brandstätter et al. (2013) assumed that an action crisis (in terms of an accumulation of perceived difficulties; cf. Carver and Scheier 1990) evokes an intrapsychic conflict and leads to reconsidering feasibility (cf. expectancy) and desirability (cf. value) of the personal goal. Reconsidering whether it is still worth pursuing the initial goal can be understood as a gradual process (Ghassemi et al. 2017). Due to the action crisis, a decisive mindset shift happens from an implemental to a more deliberate mindset (Brandstätter and Schüler 2013). Within the deliberate mindset, we assume that intraindividually, a new sequence of action phases-beginning with dropout intention formation-starts again. As intention formation is informed by students' subjective perceptions of expectancies and values (Brandstätter and Schüler 2013; Ghassemi et al. 2017; Heckhausen and Gollwitzer 1987), applying expectancy-value theory (EVT; cf. Eccles et al. 1983) seems to be fruitful for investigating the formation of dropout intention.

\section{The motivational foundation of forming dropout intention}

The majority of current studies that investigate academic decision-making in the educational context refer to the EVT of (Eccles et al. 1983; Wigfield et al. 2017). Motivation's multidimensional nature is considered by examining various components, such as success expectancy (cf. Bandura 1986), and four different components of task value (cf. Wigfield and Cambria 2010; Wigfield et al. 2017). Success expectations resemble students perceived subjective success expectation regarding whether they can successfully accomplish a task. Value includes perceptions of whether a task is pleasant (intrinsic value), important (attainment value), or useful (utility value). Fourth and least studied (cf. Flake et al. 2015), cost represents a motivational component of value in terms of the negative consequences of tasks, such as effort, psychological cost, or opportunity cost. Recently, Barron and Hulleman (2015) have argued that cost should be considered an autonomous motivational component. Beyond expectancy and value, cost provides additional information about educational outcomes, and negatively predicts academic choice (Battle and Wigfield 2003; Jiang et al. 2018). Irrespective of the ongoing debate, cost might be especially helpful for understanding the "barriers when individuals are unmotivated" (Barron and Hulleman 2015, p. 18). Despite being theoretically separable, the items measuring value have often been merged into a combined value scale (cf. Jacobs et al. 2002). Most recently, researchers began to disentangle differential contributions of value components on academic outcomes (Flake et al. 2015; Gaspard et al. 2015; Kosovich et al. 2015; Luttrell et al. 2010). Drawing on this, an in-depths analysis of the association between expectancy and different components of value (intrinsic, attainment, utility, and cost) to the formation of dropout intention seems worthwhile.

\section{Associations of expectancy and value with academic outcomes and dropout intention on an interindividual level}

Many studies apply EVT to predict academic outcomes. They mainly investigate associations of expectancy (cf. Schneider and Preckel 2017) and value (cf. Battle and Wigfield 2003) to various outcomes, such as performance and 
academic choice, often neglecting cost (Flake et al. 2015). In the existing body of literature, researchers have used different research designs. Besides cross-sectional studies (cf. Battle and Wigfield 2003), researchers conducted longitudinal studies that focused on longer periods of time ( $t>1$ year; cf. Musu-Gillette et al. 2015), and micro longitudinal studies that focused on steeper timely periods, such as over the course of one semester (cf. Dresel and Grassinger 2013). The finest timely granularity is reached by applying intensive longitudinal designs (e.g., experience sampling method; Csikszentmihalyi and Larson 2014; cf. Dietrich et al. 2017) to investigate phenomena on the situational level.

Based on the benefits of the complex designs, researchers have started to disentangle associations of expectancy and value on different levels of consideration. As Eccles et al. (1983) developed EVT to explain gender differences in science, most studies addressed differences between students (interindividual level). On the contrary, studies that addressed the perspective of changes within individuals over time focused on the intraindividual level.

In general, major findings on the interindividual level mainly result from cross-sectional, longitudinal, and microlongitudinal studies. Each motivational component provides a unique contribution to educational outcomes (cf. Barron and Hulleman 2015). Usually, expectancy beliefs are strongly related to performance outcomes (see Schneider and Preckel 2017 for a meta-analysis). In comparison, study value is considered a better predictor of academic intentions and decisions (Jiang et al. 2018; Wigfield et al. 2017). Empirically, for study dropout intention, differences between students in the initial levels of success expectations (Chemers et al. 2001; Multon et al. 1991), study value (Schiefele et al. 2007; Perez et al. 2014), and cost (Perez et al. 2014) were found to be significant predictors. Expectancy and value were found to negatively relate to dropout intention, whereas-in line with EVT-expectancy was strongly related to other academic outcomes (e.g., performance; cf. Perez et al. 2014). Additionally, cost had a positive relation to dropout intention (Grays, 2013).

Some studies also investigated a reciprocal interplay of motivation and dropout intention. Ghassemi et al. (2017) reported a reciprocal relationship between changes of appraisals of goal attainability (cf. expectancy) and desirability (cf. value) to an action crisis with regard to studies (equated to dropout intention). Students with low expectancy reported a stronger increase in dropout intention. Vice versa, higher levels of dropout intention predicted students' downgrading both expectancy and value. This provides first evidence for a reciprocal relationship between study-related values and dropout intention on the interindividual level.

To date, researchers have gained comprehensive evidence regarding the relationship between expectancy, value, and dropout intention on the interindividual level. However, research should now deepen these findings at the intraindividual level because findings from the interindividual level cannot be easily transferred to the individual level without concern for fallacy (Fisher et al. 2018; Hamaker 2012; Molenaar 2013). Accordingly, Kosovich et al. (2017) argued to reestablish research on EVT on the intraindividual level. To enrich intervention approaches and student counseling services, it is therefore necessary to focus on the intraindividual level.

\section{Associations of expectancy and value with academic outcomes and dropout intention on an intraindividual level}

As described above, forming dropout intention occurs within a phase in which students intraindividually reevaluate expectancy and value of their studies (cf. Brandstätter and Schüler 2013). Furthermore, according to Eccles (2005), a students' motivation is likely to be "shaped over time" (Eccles 2005, p. 106), and changes within students' motivation interact with dropout intention (Dresel and Grassinger 2013; Ghassemi et al. 2017). Notably, only few studies have investigated the association between motivation and dropout intention on an intraindividual level, and used intraindividual changes in motivation explicitly as a predictor of academic outcomes with respect to dropout intention. Statistically, researchers investigated how deviations from a person's mean-which resemble intraindividual changes over time-are associated to deviations in another variable on the intraindividual level.

By mainly using macro longitudinal and micro longitudinal designs, most of the existing studies rather described overall longitudinal trends of expectancy and value. In macro longitudinal studies, expectancy and value, as well as related constructs, decreased (cf. Durik et al. 2006; Jacobs et al. 2002; Musu-Gillette et al. 2015; Scherrer and Preckel 2019), but literature does not provide clear guidance in this downward trend (cf. Grays 2013; Phan 2011). The timely development of cost has not been investigated on a broader level yet. But for coursework motivation, Grays (2013) reported a general trend of increasing cost over the academic career. Micro longitudinal studies mirror these trends and revealed that students' motivation changes intraindividually (cf. Kosovich et al. 2017; Perez et al. 2014; Robinson et al. 2019). Yet, they found no consistent trend, but rather differences in the strength and valence of students' changes of expectancies and values (cf. Dresel and Grassinger 2013; Kosovich et al. 2017; Robinson et al. 2019). For some students, success expectation and the overall study value improved, or did not change at all. For others, these variables decreased. Ambiguity in overall longitudinal trends-indicated by high variation across individuals-is presumably due to personal characteristics. 
As dropout intention is a phenomenon occurring in steeper timely episodes (cf. Heublein et al. 2017), micro longitudinal studies are required to investigate the association between expectancy, value, and dropout intention on an intraindividual level. Therefore, Ghassemi et al. (2017) conducted a study over the course of four semesters within 12 measurement points. They measured expectancy and value on a broad level, as well as action crises, which can be interpreted as dropout intention. First, they found 36\% (goal attainability, cf. expectancy), 31.9\% (goal desirability, cf. value), and $39.4 \%$ (action crisis, cf. dropout intention) of the variance to be on the intraindividual level. In another intensive longitudinal study, Vancouver and Kendall (2006) reported comparable estimates of variance on the intraindividual level (e.g., $36 \%$ for students' expectancy). Second, analyses of Ghassemi et al. (2017) supported findings derived from studies on the interindividual level, showing that motivation and dropout intention were reciprocally interrelated on the intraindividual level. This means that deviations from a students' personal mean of expectancy or value were systematically related to deviations from the students' mean of dropout intention. As Ghassemi et al. (2017) investigated value on a broad level, leaving cost aside, findings on all components of value could be informative. Regarding students' effort as criterion, there is evidence from an intensive longitudinal study which took expectancy and value (intrinsic, attainment, and utility as composite score), and cost on the intraindividual level, into account (Dietrich et al. 2017). Dietrich et al. (2017) found varying patterns of results, depending on the level. On the intraindividual level, expectancy resulted as the strongest positive predictor of effort, whereas value had a rather weak, but positive, relation to effort. On the interindividual level, value was the strongest positive predictor of students' effort. On neither level was cost shown to be a relative contributor to effort.

As can be seen, intraindividual findings provide further information about the formation of dropout intention. At the same time, they indicate systematic variability between persons. For example, in line with early works of EVT, there could be gender differences. Therefore, researchers should investigate possible moderators of the association between study motivation and dropout intention.

\section{The influence of students' characteristics on the association between expectancy, value, and dropout intention}

There might be several variables that are helpful for disentangling heterogeneity within results. Heterogeneity became visible in prior works that investigated age and gender differences regarding dropout intention. For instance, Heublein et al. (2017) reported a lower dropout risk for older students and women, whereas Bonaldo and Pereira (2016) found no gender differences, but a higher risk of dropout, for older students. In most studies, students' prior achievement-in terms of grade point average (GPA) — was consistently used as a control variable (cf. Dresel and Grassinger 2013; Perez et al. 2014) because students with poorer grades were found to have higher dropout intention. Concerning the motivational reasons, Heublein et al. (2017) discovered that motivation was of higher relevance for early dropouts, and of higher importance for study dropout from humanities rather than STEM fields.

In sum, a number of variables (namely age, gender, GPA, major, and semesters studied) seem worthy to be considered as moderators in the associations of expectancy and value to dropout intention. This would meet the criticism that researchers often neglect individual differences in the relationship between academic motivation and outcomes, such as dropout intention (Rump et al. 2017).

\section{The present study}

Prior work suggests the motivational consideration of expectancy and value of studies to be the core element in the decision-making process, for example, when it comes to dropout intention (Brandstätter et al. 2013; Dresel and Grassinger 2013; Ghassemi et al. 2017). Yet the typical studies in the field of dropout phenomena focus on the association of expectancy and value on an interindividual level (cf. Perez et al. 2014; Schiefele et al. 2007), which may bias the effects. Research on study dropout is deficient in empirical findings reflecting the formation of dropout intention on an intraindividual level. Therefore, an in-depth analysis of its motivational underpinnings while controlling for interindividual differences is required. Due to strong theoretical (cf. Brandstätter and Schüler 2013; Kosovich, et al. 2017, Nagengast et al. 2013), empirical (cf. Ghassemi et al. 2017), and methodological arguments (Fisher et al. 2018), we focus on the students' intraindividual experiences regarding expectancy, value, and dropout intention over the course of one semester. Findings could provide fruitful insight for both the theoretical development of EVT in terms of a contribution to the ongoing discussion on the different components of value to academic decision-making, and in terms of gaining a deeper insight into the formation of dropout intention on an intraindividual level. Further, findings could be of practical value to student counselors on how to properly address dropout phenomena with regard to students' characteristics.

Consequently, the aim of our study was to provide a thorough and in-depth investigation of intraindividual motivational processes while forming dropout intention. First, in line with works of Ghassemi et al. (2017), we sought to replicate and extend findings on expectancy and different 
components of study value (intrinsic, attainment, utility, and cost) and their association to dropout intention. Our first research question aims at disentangling the contribution of different motivational components to dropout intention on the intraindividual level over the course of one semester, and can be summarized into the following hypotheses:

Hypothesis 1 Deviations from the individual mean of expectancy are substantially negatively associated with deviations from the individual mean of dropout intention.

Hypotheses $2 a-d$ Deviations from the individual means of the positive components of study value ( $2 \mathrm{a}$ intrinsic, $2 \mathrm{~b}$ attainment, 2c utility) are substantially negatively associated with deviations from the individual mean of dropout intention. Deviations from the individual mean of the negative component of study value $(2 \mathrm{~d}, \mathrm{cost})$ are substantially positively associated with deviations from the individual mean of dropout intention.

Second, we investigated whether for some students, motivation is of higher importance with regard to dropout intention than for other students. Thereby, the strength of the associations of motivation and dropout intention might differ interindividually. Personal characteristics, such as age, gender, GPA, major, or semesters studied, could be possible moderators for this (cf. Heublein 2014; Heublein et al. 2017). For instance, motivation seems to be of higher importance for dropout intention of students having poorer GPA, enrolled in STEM majors, or being in the first semesters compared with students having higher GPA, studying humanities, or being in a higher semester. Due to the ambiguous empirical basis, we make an exploratory investigation of the effect of age and gender.

Research Questions 3a, b Do the invariant person characteristics age (3a) and gender (3b)moderate the intraindividual strength of the association between motivation (expectancy,intrinsic, attainment, utility and cost) and study dropout intention?

Hypothesis $3 c-e$ The association between motivation and dropout intention is presumed to be stronger for students with poorer GPA (3c), with a STEM major (3d), and first semester students (3e).

\section{Method}

\section{Procedure and participants}

We conducted a micro longitudinal study with three points of measurement over the course of one semester. Prior to data collection, the university's ethics committee eximined and approved the study with regard to ethics and data protection law. The recruitment process took place at the beginning of the 2017/2018 fall semester. We approached students during their lectures and gave them brief information about the study. Interested students voluntarily filled in a contact form and shortly afterwards attended an introductory session (T1), where they received further information about the study and data privacy issues, and obtained and completed a written informed consent. Afterwards, they received a link leading to the online survey.

The sample consisted of $N=326$ ( $n=218$ female) undergraduate students of math $(n=101)$ and law $(n=225)$. The chosen majors have a particularly high dropout prevalence in Germany (Heublein 2014). We excluded students from the analyses who reported another major $(n=6)$ or did not complete the first questionnaire $(n=4)$. Student's mean age was 20.50 years $(\mathrm{SD}=2.51)$. At the beginning of the study, they had studied for $2.85(\mathrm{SD}=2.33)$ semesters. All students completed the first online questionnaire at the beginning of the semester (T1), 266 answered the second questionnaire in the middle of the semester (T2), and 236 finished the third questionnaire at the end of the semester (T3). Time lags between the measurement points T1 to T3 averaged 6 weeks. The dropout rate (28.48\% from $\mathrm{T} 1$ to $\mathrm{T} 3$ ) was satisfactory. To reward students for their effort, they received up to $20 €$, depending on their compliance rate. In this paper, we present data that is relevant to the underlying research question.

\section{Time varying variables (intraindividual level)}

At all points of measurement, we investigated the time varying variables that explicitly focused on students' majors. Unless indicated, the response format for all scales was a four-point Likert scale running from 1 (disagree) to 4 (agree). Higher values in the results section indicate a stronger expression of the variable.

\section{Dropout intention}

We used five items (e.g., "I often think about changing my major or dropping out of university") developed by Dresel and Grassinger (2013) to determine students' strength of intention to either change major or drop out of university. Students answered the items on a 7-point Likert-type scale $(1=$ absolutely inapplicable, $7=$ absolutely applicable $)$. The measure yielded good internal consistency at $\mathrm{T} 1$ in our study (Cronbach's $\alpha=0.86$ ).

\section{Motivation}

To assess students' expectancy, we used three items (e.g., "I believe that I can be successful in my major") initially 
developed by Kosovich et al. (2015), translated into German and adapted to the academic context by Fleischer et al. (2019). In our study, internal consistency at T1 was satisfactory (Cronbach's $\alpha=0.74$ ).

Based on our EVT framework, we used 23 items originally developed by Gaspard et al. (2017) for the school context to ask students about their subjective value of studies. We adapted relevant subscales and items to the university context. The first subscale is intrinsic value (3 items, e.g., "I enjoy dealing with the content in my major", Cronbach's $\alpha_{\mathrm{T} 1}=0.85$ ), the second is attainment value (6 items, e.g., "It is important to me to be good at my major", Cronbach's $\alpha_{\mathrm{T} 1}=0.85$ ), the third is utility value of studies for future job (4 items, e.g., "The content within my major will benefit me later on in my professional life.", Cronbach's $\alpha_{\mathrm{T} 1}=0.70$ ), and the fourth is cost in terms of effort, psychological and opportunity cost (10 items, e.g., "I have to give up a lot to do well in my major", Cronbach's $\alpha_{T 1}=0.87$ ).

\section{Time invariant variables (interindividual level)}

At T1, participants reported time invariant sociodemographic data. Students provided information on their age, gender, major, semesters studied, and GPA of their diploma (German Abitur), which provides access to higher education. The average scores of the German Abitur range from 1.0 (very good) to 4.0 (sufficient).

\section{Analyses}

Longitudinal data-implying that the same participants are being surveyed repeatedly - enable researchers to investigate complex psychological processes that unfold over time. At the same time, the hierarchical data structure (measurement points nested in individuals) leads to dependency among the measures (Bryk and Raudenbush 1987; Singer and Willett 2003) and thereby violates assumptions underlying the general linear model (GLM). Neglecting the hierarchical structure can lead to biased results (cf. ecological fallacy; Freedman 1999) because associations at the different levels are independent, and sometimes of opposite directions (Nezlek 2011; Vancouver and Kendall 2006). Extending the GLM by one level of analysis to hierarchical linear models (HLM; Raudenbush and Bryk 2002) accounts for methodological and theoretical challenges in the data. Researchers also refer to these models as multilevel models (Goldstein 1987), and commonly use them in life course sciences (Mund and Nestler 2019) for longitudinal data (Luke 2004). In sociology and econometrics, a similar approach-the fixed effects regression model — is more widely used (Wooldridge 2010). Both statistical approaches share certain formal similarities (e.g., variance decomposition on multiple levels). But they also show differences (e.g., with regard to underlying assumptions on the normal distribution of the intercept, or regarding exogeneity of the residuals that fixed effects models do not pose; for a further discussion, see Hosoya et al. 2014). We opted for using multilevel models as only multilevel models enable researchers to investigate associations of intraindividual changes to time varying and time invariant predictors, and to consider time as a predictor itself (Singer and Willet 2003; Snijders 1996). Thereby, we use time and the motivational components as predictors to observations of dropout intention on the lowest level (Level 1, intraindividual level) which are nested in individuals on a higher level (Level 2, interindividual level). Notably, we will speak of levels when it comes to technical details of the models, and address effects on the intraindividual level as withinperson effects, and effects on the interindividual level as between-person effects.

In general, multilevel models allow us to simultaneously investigate different effects which are located at these different levels (Raudenbush and Bryk 2002; Snijders and Bosker 1999). On the one hand, multilevel models allow us to test for between-person effects (e.g., if student A has a higher success expectation than student $\mathrm{B}$, he or she will have a lower dropout intention than B). On the other hand, the model can inform about within-person effects on which we focus in this study (e.g., a student whose expectancy deviates negatively from his/her mean over time reports a positive deviation from his/her mean in dropout intention at the same time). Moreover, it is possible to investigate cross-level interactions (e.g., does the relative strength of the association between success expectation and dropout intention depend on person characteristics such as gender?).

We tested several models in our multilevel analyses. To start with, by computing the null model (Model 0), we determined the intra-class correlation (ICC; Cohen et al. 2014) of our criterion. The ICC shows the proportion of variance for the criterion found on the between level in relation to the overall variance of the criterion, and thus indicates whether multilevel analyses are warranted (Cohen et al. 2014).

Then, we conducted random intercept and random slope models, allowing all individuals to differ in their initial levels (intercepts) and strength of the associations between predictor and outcome (slopes). Including intercept and slope as random coefficients is quite common in multilevel modeling, and discussed as a strength of the models, because it accounts for variation within and between individuals (Nezlek et al. 2006). In the first two random intercept and random slope models, we only focused on within-person associations. Equivalent to testing hypotheses in GLM, we chose to test the effect of all Level-1 predictors (time and motivational components) on deviations in dropout intention in a series. In the first model (Model 1), we only used time as a predictor for longitudinal changes in dropout intention (because the slope resembles the overall longitudinal 
development; cf. Singer and Willett 2003). In the second model (Model 2), we further investigated the within effect of deviations in the different motivational components over time on deviations in dropout intention (Hypotheses 1 and 2a-d), thereby controlling for time as a predictor. Given the case that the slopes for the associations between motivation and dropout intention could turn out to vary significantly between the persons in Model 2, we planned to investigate a third model as well. By this Model 3, we wanted to test whether time-invariant characteristics (age, gender, GPA, major, and semesters studied) explain significant variance in these slopes. Hence, by introducing cross-level interactions (cf. Luke 2004) for all significantly varying slopes to Model 3, we investigated Research Questions 3a, b and Hypothesis $3 \mathrm{c}-\mathrm{e}$ simultaneously.

In all of our multilevel models, our Level 1 predictor time (coded as $0=\mathrm{T} 1,1=\mathrm{T} 2,2=\mathrm{T} 3$ ) has not been centered, so the intercept resembles the starting value of dropout intention at T1. Concerning the other Level 1 predictors of expectancy and study value, we applied group mean centering, as suggested by Enders and Tofighi (2007). The predictor variables on Level 2 were age, GPA, and semesters studied, which were grand-mean centered continuous variables, as well as gender ( $\operatorname{coded}$ as $0=$ female, $1=$ male), and major (codes as $0=$ laws, $1=$ math).

Referring to recent simulation studies on sample size, the limiting factor in a two-level multilevel analysis is the group-level sample size (Level 2), which is more important than the total sample size (Level 1; cf. Maas and Hox 2005). To obtain unbiased estimates, Maas and Hox (2005) define a group size $>50$ as acceptable. Our sample size on Level 2 was $n=326$ and therefore clearly above the sufficient size for multilevel analyses. To maximize the possibility of finding cross-level interactions, we drew on previous works and tested the cross-level interaction effects at a significance level of $\mathrm{p}<0.10$ (Snijders and Bosker 1999; Yeo and Neal 2008). We tested all other effects at $p<0.05$. With regard to effect sizes, currently there is no consensus in multilevel modeling (Kreft and de Leeuw 1998; Nezlek 2011). We applied multilevel analysis using Mplus 8.3. (Muthén and Muthén 1998-2017) using the robust maximum likelihood estimator. Missing data was imputed via the full information maximum likelihood (FIML) approach (Enders 2010), which is favored above other missing data strategies (e.g., listwise deletion; Schafer and Graham 2002) and implemented as default (Muthén and Muthén 1998-2017).

\section{Results}

\section{Panel mortality}

First, we considered the attrition of participants from the current study and its possible associations to our variables of interest. Out of the total sample $(N=326), n=225$, students completed all questionnaires at all measurement times ( $\mathrm{T} 1$ to T3), $n=54$ answered only two questionnaires (either T1 and $\mathrm{T} 2$ or T1 and T3), and at least $n=49$ students answered only at T1. In total, $N=828$ observations on Level 1 were nested in $n=326$ individuals on Level 2. A one-way ANOVA revealed no significant mean differences between the initial sample at $\mathrm{T} 1$ and those who left the current study at $\mathrm{T} 2$ or T3 regarding dropout intention, $F(2,325)=0.59, p=0.56$, expectancy, $F(2,325)=0.71, p=0.49$, intrinsic value, $F(2$, $325)=0.05, p=0.95$, attainment value $F(2,325)=0.1 .18$, $p=0.31$, utility value $F(2,325)=2.98, p=0.05$, and study cost, $F(2,325)=0.12, p=0.89$. As a result, we decided to use all available data.

\section{Descriptive and preliminary results}

Table 1 reports descriptive statistics (means and standard deviations) for all variables of interest at all measurement points. The mean of dropout intention was below the scale mean but with a high standard deviation. The mean of expectancy and the positive components of study value were situated above the scale mean, whereas study cost matched the scale mean at T1. All variables showed a general tendency of change in their means over time. Dropout intention and cost of studies increased over the course of the semester, expectancy, intrinsic value, attainment value, and utility value decreased.
Table 1 Descriptive statistics of all variables at all measurement times

\begin{tabular}{|c|c|c|c|c|c|c|}
\hline \multirow[t]{2}{*}{ Measure } & \multicolumn{2}{|l|}{$\mathrm{T} 1$} & \multicolumn{2}{|l|}{$\mathrm{T} 2$} & \multicolumn{2}{|l|}{$\mathrm{T} 3$} \\
\hline & M & SD & M & SD & M & SD \\
\hline Dropout intention & 2.15 & 1.33 & 2.37 & 1.46 & 2.52 & 1.62 \\
\hline Expectancy & 3.26 & 0.54 & 3.22 & 0.58 & 3.20 & 0.61 \\
\hline Intrinsic value & 3.29 & 0.60 & 3.22 & 0.62 & 3.16 & 0.65 \\
\hline Attainment value & 3.53 & 0.51 & 3.42 & 0.53 & 3.28 & 0.62 \\
\hline Utility value & 3.08 & 0.56 & 2.99 & 0.62 & 2.99 & 0.65 \\
\hline Cost & 2.48 & 0.57 & 2.59 & 0.59 & 2.68 & 0.60 \\
\hline
\end{tabular}

The scale of dropout intention ranges from 1-7, all others from 1-4 
We present the intercorrelations at the interindividual level in Table 2. At all times, the correlations of dropout intention to expectancy and intrinsic, attainment, and utility value were negative, whereas the correlations between dropout intention and cost were positive. Expectancy showed a midsized correlation to dropout intention. The four components of value differed in the strength of correlation. Intrinsic value and cost highly correlated with dropout intention, while attainment value showed midsized, and utility value small to midsized correlations. Gender and GPA substantially correlated with dropout intention at T1 (see Table 3). Both correlations were small (Cohen 1988) and indicated that female students had a higher dropout intention. Poorer GPA (indicated by higher values on the GPA) related to a higher dropout intention. At T3, we found small negative correlations of dropout intention with age and semesters studied, and small positive correlations with GPA.

\section{Intraindividual associations of expectancy, value, and dropout intention}

First of all, by computing Model 0 (null model), we investigated the ICC for study dropout. We found $61 \%$ of the variance in dropout intention was between persons, consequently $39 \%$ of all variance was within persons. Literature suggests applying multilevel models for ICCs $>5 \%$ of variance on Level 2 (Cohen et al. 2014). Therefore, multilevel analyses were warranted in our case.

In a second step, we computed Model $1-$ a random intercept and random slope model with time as a Level 1 predictor for longitudinal changes in study dropout intention. As can be seen from Table 4, time significantly predicted dropout intention $\left(B_{1}=0.20, \mathrm{SE}=0.05, p<0.001\right)$, indicating an increase of dropout intention from the beginning of the semester until the final exam phase.

In a third step, to test Hypotheses 1a-e, we simultaneously included expectancy and all components of value as further Level 1 predictors in Model 2. Thus, we disentangled the association of each component of motivation by analyzing whether intraindividual changes in expectancy, intrinsic value, attainment value, utility value, and cost were related to intraindividual changes in study dropout intention over the course of one semester. Due to group mean centering, every student varied around his or her own mean over time. A regression coefficient of $\mathrm{B}>0$ indicates a positive relationship between deviations in the predictor and deviations in dropout intention. For example, an increase above the persons mean on the predictor is associated with an increase in study dropout intention. $\mathrm{B}<0$ indicates a negative relationship, and $\mathrm{B}=0$ indicates that there is no association between deviations in the predictor and deviations in the criterion.

The results concerning Model 2 showed that deviations in intrinsic value $\left(B_{3}=-0.33, \mathrm{SE}=0.13, p=0.007\right)$, attainment value $\left(B_{4}=-0.30, S E=0.13, p=0.02\right)$, and study cost $\left(B_{6}=0.67, \mathrm{SE}=0.11, p<0.001\right)$ were significantly associated with deviations in dropout intention. As expected in Hypothesis $2 a$ (intrinsic value) and $2 b$ (attainment value), we found a countervailing pattern. For cost (Hypothesis 2e), we found a proportional pattern because positive deviations in costs came along with positive deviations in dropout intention. Contrary to the results in Model 1, the effect of time on dropout intention vanished $\left(B_{1}=0.03, \mathrm{SE}=0.04, p=0.45\right)$, when the motivational predictors were entered in the model. We also found no significant associations between deviations in expectancy $\left(B_{2}=-0.02, \mathrm{SE}=0.12, p=0.87\right)$ and utility value $\left(B_{5}=0.20\right.$, $\mathrm{SE}=0.12, p=0.09)$ with deviations in dropout intention within students.

\section{Interindividual differences in associations of motivation to dropout intention}

Model 2 also allowed conclusions concerning interindividual differences in the association of deviations (slopes) in the different motivational components and deviations in dropout intention. Considering the significance of variations in the slopes, we found that the slope of expectancy yielded no significant variation across persons ( $\operatorname{Var}=0.15, p=0.55$ ). For intrinsic value, the overall slope varied substantially between persons ( $\operatorname{Var}=0.39, p=0.04$ ). The slope of attainment value showed no substantial variation across persons $(\operatorname{Var}=0.30$, $p=0.41)$ and the same was true for the slope of utility value (Var $=0.60, p=0.07)$. Cost showed substantial variation between persons ( $\operatorname{Var}=0.54, p=0.03$ ).

To further investigate whether our proposed demographic variables (age, gender, GPA, major, semesters studied) can explain the variance in the slopes of deviations in intrinsic value or cost with deviations in dropout intentions, we tested Model 3. Therefore, we entered cross-level interaction effects of the Level 2 variables age (3a), gender (3b), GPA (3c), students' major (3d), and the semesters studied (3e) with the Level 1 slopes of intrinsic value and cost into Model 3. Of all moderators, gender, GPA, major, and semesters studied could not explain variation in the slopes between motivation and dropout intention (see Table 4). Only age was found to significantly influence the relationship between intrinsic value and dropout intention $\left(B_{7}=0.06, \mathrm{SE}=0.03, p=0.04\right)$. Thereby, age reduces the negative relationship between intrinsic value and dropout intention. In other words, the effect of intrinsic value is stronger for younger students.

\section{Discussion}

Low study motivation is considered as one of the most important predictors of study dropout (cf. Dresel and Grassinger 2013; Heublein 2014; Jiang et al. 2018). To date, 


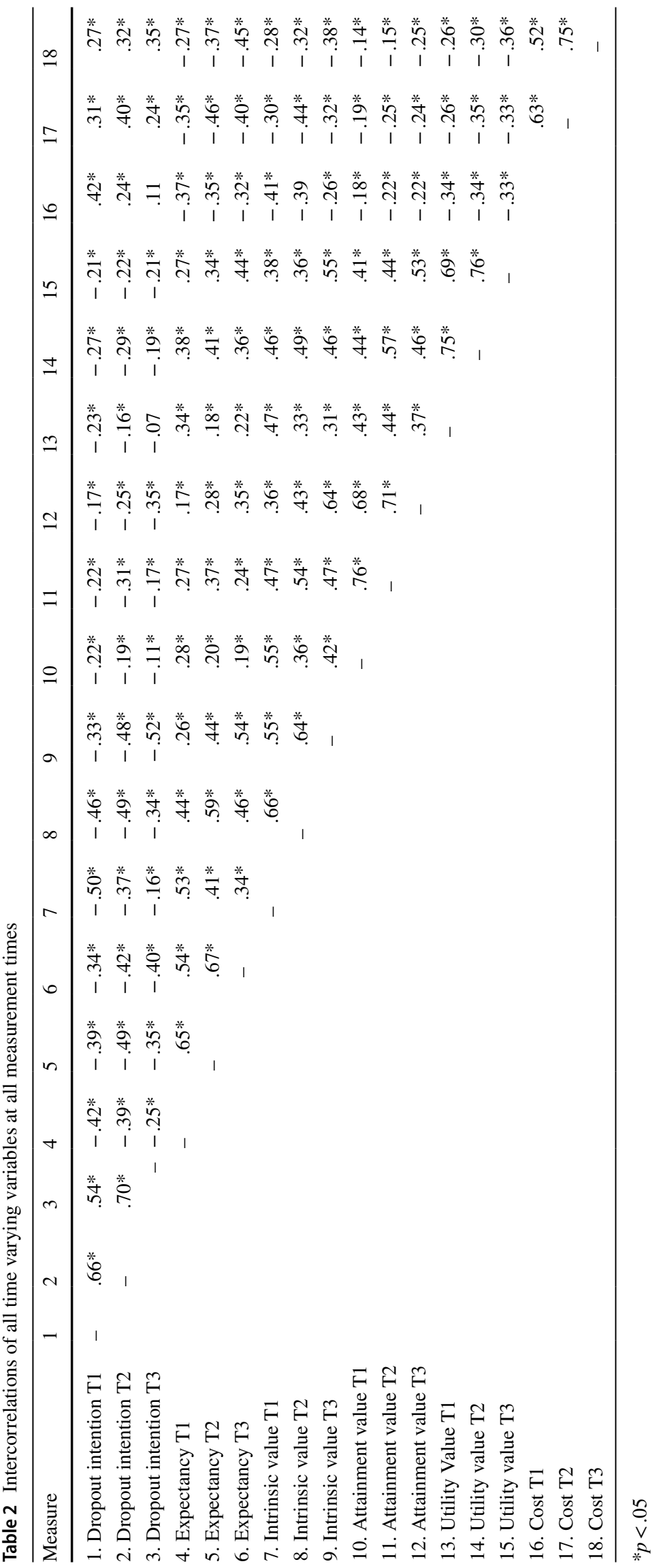


Table 3 Intercorrelations of all time invariant variables with dropout intention at all measurement times

\begin{tabular}{lcccccccc}
\hline Measure & 1 & 2 & 3 & 4 & 5 & 6 & 7 & 8 \\
\hline 1. Age & - & $.16^{*}$ & $.12^{*}$ & $.13^{*}$ & $.52^{*}$ & -.00 & -.08 & $-.16^{*}$ \\
2. Gender $(0=$ female $)$ & & - & $-.06^{*}$ & $.26^{*}$ & .09 & $-.12^{*}$ & -.09 & -.01 \\
3. GPA & & & - & $-.11^{*}$ & .04 & $.21^{*}$ & .06 & $.18^{*}$ \\
4. Major $(0=$ laws $)$ & & & & - & $.11^{*}$ & .03 & .11 & .12 \\
5. Semester & & & & - & .06 & -.09 & $-.16^{*}$ \\
6. Dropout intention T1 & & & & & - & $.66^{*}$ & $.54^{*}$ \\
7. Dropout intention T2 & & & & & & - & $.70^{*}$ \\
8. Dropout intention T3 & & & & & & & - \\
\hline
\end{tabular}

$* p<.05$
Table 4 Estimates from multilevel models 0 to 3

\begin{tabular}{|c|c|c|c|c|c|c|c|c|}
\hline & \multicolumn{2}{|l|}{ Model 0} & \multicolumn{2}{|l|}{ Model 1} & \multicolumn{2}{|l|}{ Model 2} & \multicolumn{2}{|l|}{ Model 3} \\
\hline & Estimate & SE & Estimate & SE & Estimate & SE & Estimate & SE \\
\hline \multicolumn{9}{|l|}{ Fixed effects $(b)$} \\
\hline Intercept & $2.32 *$ & 0.07 & $2.16^{*}$ & 0.07 & $2.30 *$ & 0.08 & $2.30 *$ & 0.08 \\
\hline Time & & & $0.20^{*}$ & 0.05 & 0.03 & 0.04 & 0.03 & 0.04 \\
\hline Expectancy & & & & & -0.02 & 0.12 & -0.01 & 0.12 \\
\hline Intrinsic value & & & & & $-0.33^{*}$ & 0.12 & - & - \\
\hline Attainment value & & & & & $-0.30 *$ & 0.13 & $-0.30 *$ & 0.13 \\
\hline Utility value & & & & & 0.20 & 0.12 & 0.21 & 0.12 \\
\hline Cost & & & & & $0.67 *$ & 0.11 & - & - \\
\hline \multicolumn{9}{|l|}{ Random effects } \\
\hline \multicolumn{9}{|l|}{ Level 1 (variances) } \\
\hline Residual & $0.83 *$ & 0.09 & $0.57 *$ & 0.07 & $0.31 *$ & 0.06 & $0.32 *$ & 0.06 \\
\hline \multicolumn{9}{|l|}{ Level 2 (variances) } \\
\hline Intercept & $1.33^{*}$ & 0.16 & $1.21 *$ & 0.18 & $1.52 *$ & 0.19 & $1.51 *$ & 0.16 \\
\hline Slope time & & & $0.22 *$ & 0.07 & 0.06 & 0.05 & 0.06 & 0.04 \\
\hline Slope expectancy & & & & & 0.15 & 0.25 & 0.06 & 0.47 \\
\hline Slope intrinsic value & & & & & $0.39 *$ & 0.19 & - & - \\
\hline Slope attainment value & & & & & 0.30 & 0.37 & 0.25 & 0.36 \\
\hline Slope utility value & & & & & 0.60 & 0.33 & 0.55 & 0.36 \\
\hline Slope cost & & & & & $0.54 *$ & 0.25 & - & - \\
\hline Residual intrinsic value & & & & & & & 0.36 & 0.23 \\
\hline Residual cost & & & & & & & 0.63 & 0.38 \\
\hline \multicolumn{9}{|l|}{ Cross-level interaction } \\
\hline Intrinsic value $\times$ age & & & & & & & $0.06^{*}$ & 0.03 \\
\hline Intrinsic value $\times$ gender & & & & & & & 0.01 & 0.25 \\
\hline Intrinsic value $\times$ GPA & & & & & & & 0.06 & 0.14 \\
\hline Intrinsic value $\times$ major & & & & & & & 0.05 & 0.27 \\
\hline Intrinsic value $\times$ semester & & & & & & & 0.02 & 0.05 \\
\hline Cost $\times$ age & & & & & & & -0.01 & 0.03 \\
\hline Cost $\times$ gender & & & & & & & -0.18 & 0.23 \\
\hline Cost $\times$ GPA & & & & & & & -0.20 & 0.31 \\
\hline Cost $\times$ major & & & & & & & -0.36 & 0.25 \\
\hline Cost $\times$ semester & & & & & & & -0.03 & 0.04 \\
\hline Intra-class correlation & 0.61 & & & & & & & \\
\hline
\end{tabular}

$* p<.05$ 
micro longitudinal studies on the intraindividual association of motivation to forming dropout intention are sparse. To help close this research gap, our study took an EVT perspective (cf. Eccles et al. 1983) and primarily targeted the associations of expectancy and value (intrinsic, attainment, utility, and cost) to dropout intention over the course of one semester on an intraindividual level. As existing works report substantial heterogeneity in findings referring to dropout intention, we considered students' demographics (age, gender, GPA, major, semesters' studied) as possible moderators to the strength of the association between motivation and dropout intention.

First of all, preliminary analyses revealed that $39 \%$ of variance in dropout intention are on the intraindividual level (changes in a persons' mean within a person over time), suggesting that $61 \%$ of the total variance can be explained by group effects. In our data, a group resembles a single person (between-person level) because measurement occasions (within-person level) are clustered in individuals. Our findings are comparable to findings of Ghassemi et al. (2017), who found $39.4 \%$ of variance in dropout intention on the intraindividual level.

We applied different multilevel models to account for the hierarchical structure in our data, and to investigate the differential relations of time varying motivational components and their interaction with time-invariant demographics with dropout intention. By using a random intercept and random slope model, we found time to be positively and substantially related to dropout intention (Model 1). From the beginning to the end of the semester, dropout intention increased in our sample, consistent with findings of a macro longitudinal study of Heublein et al. (2017). By simultaneously integrating expectancy and value (intrinsic, attainment, utility, and cost) to another random intercept and random slope model (Model 2), we found deviations in dropout intention were significantly related to deviations in intrinsic value, attainment value, and cost, supporting Hypothesis $1 \mathrm{~b}$, c, and e. Specifically, a decrease in intrinsic and attainment value was associated with an increase in dropout intention, whereas an increase in cost was intraindividually related to an increase in dropout intention. The significant effect of time on dropout intention disappeared. Contrary to our assumptions, we found no effect for expectancy and utility value, thus we find no empirical support for Hypotheses 1a and2d.

Our findings correspond to studies on the interindividual (Battle and Wigfield 2003; Dresel and Grassinger 2013) and intraindividual level (Ghassemi et al. 2017). In line with EVT, we found that values are more strongly related to academic choice compared to expectancy (cf. Jiang et al. 2018; Wigfield and Cambria 2010; Wigfield et al. 2017). However, with regard to the strong bivariate relationship between expectancy and value, our results might reflect that once the different components of value are entered to predict dropout intention, expectancy has no predictive power beyond the components of value. In future studies, the interaction-terms between expectancy and value could be addressed, which prove worthwhile for performance outcomes (cf. Meyer et al. 2019).

Interestingly, intrinsic value, attainment value, and cost were the significant predictors of dropout intention. Researchers have often highlighted the role of intrinsic value for different outcomes (cf. Richardson et al. 2012). Attainment value also played a central role for study success (Robbins et al. 2004). Cost also showed a substantial relation to dropout intention, which fits well into findings from the interindividual level (cf. Battle and Wigfield 2003; Grays 2013; Jiang et al. 2018), underlining the importance of including measures of cost into future studies on the intraindividual level. As a side note, with regard to the ongoing debate of whether cost is a separate component or a subcomponent of value, Wigfield et al. (2017, p. 125) state "cost should be considered an influence on values rather than an aspect of values". Further studies are needed to reveal insights into the relationship between the positive components of value and cost. It would be worthwhile to investigate the interplay of value and cost in terms of buffering effects. In doing so, it seems fruitful to further address the role of cost in the dropout process in future research more precisely regarding the presumed components of cost, namely effort, psychological cost and opportunity cost (Eccles et al. 1983; Wigfield et al. 2017).

Contrary to expectations, changes in perceived utility value- though often targeted in trainings and interventions to foster academic outcomes and participation in the STEM field (cf. Rosenzweig and Wigfield 2016; Rosenzweig et al. 2020) — did not relate to changes in dropout intention. This result is in line with the results of Rump et al. (2017), who found the weakest effect for extrinsic motivation to dropout intention (compared to a strong effect of intrinsic motivation). It is noteworthy to stress that we found only a slight mean level change in utility value on a descriptive level from $\mathrm{T} 1$ to $\mathrm{T} 2$. Thus, there was only low variance in utility value, which might explain our non-significant finding. As suggested by Kosovich et al. (2017), utility value is potentially less explicit in students' perceptions, and might therefore be a more stable attitude.

Another, more general consideration targets the relation between predictor and criterion. In our multilevel regression models, we considered changes in motivation as predictors of changes in dropout intention. Research on goaldisengagement (Brandstätter et al. 2013; Heckhausen and Heckhausen 2018) has suggested the opposite direction of effects. Brandstätter and Schüler (2013) presumed an adaptive mechanism of deliberately devaluating the initial goal, thereby dropout intention would affect motivation in order to maintain well-being (Brandstätter and Schüler 2013). Thus, 
a decrease in study value could be due to an intraindividual change in dropout intention. Ghassemi et al. (2017) tested this relationship and found evidence of a reciprocal relationship between a composite score of value and dropout intention. Future research could empirically test whether this presumption holds true for each component of value.

Our results also inform about substantial interindividual variation in the slopes of motivation and dropout intention (see Model 2). We were interested in investigating whether students' demographics could explain variance in the slopes of motivation and dropout intention (Hypothesis $3 \mathrm{a}-\mathrm{e}$ ). Since only the slopes of intrinsic value and cost varied substantially between persons, we further investigated crosslevel interactions for age, gender, GPA, major, and semesters studied as demographic Level 2 variables. Among all possible moderators, only age accounted for interindividual differences in the association between intrinsic value and dropout intention. We found that the effect of intrinsic value was stronger for younger students. This is in line with a similar study of Rump et al. (2017), who reported especially young students' decision to drop out to be strongly influenced by intrinsic motivation. To disentangle interindividual variation in the relationship between cost and dropout intention, future studies should consider further moderators (e.g., support of family and friends, health). Additionally, future studies could broaden the scope to interaction effects between the initial values (intercepts) of motivation and dropout intention on the between-person level.

In sum, our study offers insights into the differential contributions of each of the value components to dropout intention. Students were able to differentiate between different components of value, contrary to findings of Battle and Wigfield (2003), and Perez et al. (2014). When students (intraindividually) perceive studying is less fun (intrinsic value), less important (attainment value), and too costly, they are more prone to drop out. Based on these differentiated findings, we recommend directing counseling services toward these motivational components. However, although study dropout often has negative connotations (with regard to society and institutions of higher education), students' subjective evaluation of their dropout might be different. For some students, study dropout can be functional (Pascarella and Terenzini 1980) in terms of an adaptive goal shift because the adherence to unattainable goals is associated with negative consequences for well-being (Wrosch et al. 2003). Future research should find out in which cases counselors should address certain components of motivation and recommend continuing studies-in contrast to cases where dropping out of university is advisable.

With regard to the intraindividual changes which occur over time, new research questions have arisen concerning the causes which lead to intraindividual changes in study motivation over the course of one semester. Initial evidence has indicated that unfulfilled expectations and unfulfilled study values are associated with a decline in expectations and study values (Grassinger 2018). Another reason could be due to the institutional or instructional features of students' lectures or courses, which could lead to the perception of increasing cost. When confronted with disappointment or increasing cost, motivation regulation (Miele and Scholer 2018) could be an element that mediates change in student dropout intention. Research on motivational regulation revealed its beneficial effect on student performance and well-being, as well as its mediating role in predicting study dropout (Bäulke et al. 2018; Grunschel et al. 2016). A more thorough understanding of the motivation regulation process could aid the work of student counselors.

\section{Limitations}

Theoretically, there is a difference between the intention to drop out of university and the intention to change majors (Hovdhaugen 2009). Dropout students differ from students who change majors in terms of interests and beliefs in their own abilities (Multrus et al. 2005). We admit that we did not differentiate between the intention to drop out of university and the intention to change majors because we were interested in any intentions related to dropping out of math and law studies. Therefore, it did not matter to us whether students were about to quit university completely or select another major. Thus, if only leaving a particular major is of interest, this distinction would not have to be made.

Further, framing the dropout process in the action phase model and describing it in terms of a gradual sequence of states (from first thoughts to final deregistration) is a first approximation to provide a theoretical framework for the process itself. Hence, it requires a more profound theoretic rationale to explain the process in detail, which would have gone beyond the scope of our study. An instrument to diagnose the current state in the dropout process would be beneficial for the field to reveal in which phases motivation has the most significant impact.

Another limitation concerns the number of measurement points. It would be insightful to analyze data from a fourth measurement point at the beginning of the next semester to track the effect of term breaks on dropout intention and motivation. Presumably, students recover from the exhausting semester during their vacation, and return with fresh motivation and strengths to face a new semester, where the same process, as illustrated in our data, might resume. 


\section{Conclusion}

Study dropout from university is a common politically and socially relevant phenomenon - for students, university, and society. Yet the typical studies on dropout intention focus on interindividual differences, may bias the effects, and do not inform about the intraindividual process. The results of this study conceptually enrich existing research by uncovering the dynamic process in terms of its motivational background and the different contributions of expectancy, and all components of value (intrinsic, attainment, utility value, as well as cost; cf. Eccles et al. 1983), to forming dropout intention. Further, we showed that students' demographics mostly do not affect the association between motivation and dropout intention (except for the moderating effect of age on the association between intrinsic value and dropout intention). In sum, our study sheds light on this phenomenon from a multidimensional and dynamic perspective. Intraindividually, intrinsic and attainment value, as well as cost, substantially relate to increasing dropout intention over the course of one semester at university. When studying seems to entail more pain than gain, students are prone to drop out.

Acknowledgements Open Access funding provided by Projekt DEAL.

Funding This study was funded by the German Federal Ministry of Education and Research (Bundesministerium für Bildung und Forschung, BMBF, Grant Number 01PX16011 A).

\section{Compliance with ethical standards}

Conflict of interest All authors declare that they have no conflict of interest.

Ethical approval All procedures performed in studies involving human participants were in accordance with the ethical standards of the institutional and/or national research committee and with the 1964 Helsinki declaration and its later amendments or comparable ethical standards. This article does not contain any studies with animals performed by any of the authors.

Open Access This article is licensed under a Creative Commons Attribution 4.0 International License, which permits use, sharing, adaptation, distribution and reproduction in any medium or format, as long as you give appropriate credit to the original author(s) and the source, provide a link to the Creative Commons licence, and indicate if changes were made. The images or other third party material in this article are included in the article's Creative Commons licence, unless indicated otherwise in a credit line to the material. If material is not included in the article's Creative Commons licence and your intended use is not permitted by statutory regulation or exceeds the permitted use, you will need to obtain permission directly from the copyright holder. To view a copy of this licence, visit http://creativecommons.org/licenses/by/4.0/.

\section{References}

Ajzen, I. (1991). The theory of planned behavior. Organizational Behavior and Human Decision Processes, 50, 179-211. https:// doi.org/10.1016/0749-5978(91)90020-T.

Alarcon, G. M., \& Edwards, J. M. (2013). Ability and motivation: Assessing individual factors that contribute to university retention. Journal of Educational Psychology, 105(1), 129-137. https ://doi.org/10.1037/a0028496.

Alban, M., \& Mauricio, D. (2019). Predicting university dropout through data mining: A systematic literature. Indian Journal of Science and Technology, 12(4), 1-12. https://doi.org/10.17485/ ijst/2019/v12i4/139729.

Bandura, A. (1986). Social foundations of thought and action. Englewood Cliffs, NJ: Prentice Hall.

Barron, K. E., \& Hulleman, C. S. (2015). Expectancy-value-cost model of motivation. Psychology, 84, 261-271. https://doi.org/10.1016/ B978-0-08-097086-8.26099-6.

Battle, A., \& Wigfield, A. (2003). College women's value orientations toward family, career, and graduate school. Journal of Vocational Behavior, 62(1), 56-75. https://doi.org/10.1016/S0001 -8791(02)00037-4.

Bäulke, L., Eckerlein, N., \& Dresel, M. (2018). Interrelations between motivational regulation, procrastination and college dropout intentions. Unterrichtswissenschaft, 46(4), 461-479. https://doi. org/10.1007/s42010-018-0029-5.

Bean, J. P. (1982). Conceptual models of student attrition: How theory can help the institutional researcher. New Directions for Institutional Research, 1982(36), 17-33. https://doi.org/10.1002/ ir.37019823604.

Berger, J. B., \& Lyon, S. C. (2005). Past to present: A historical look at retention. In A. Seidman (Ed.), College student retention: Formula for student success (pp. 1-30). Wesport, CT: Praeger.

Bonaldo, L., \& Pereira, L. N. (2016). Dropout: Demographic profile of Brazilian university students. Procedia-Social and Behavioral Sciences, 228, 138-143. https://doi.org/10.1016/j.sbspr o.2016.07.020.

Bound, J., \& Turner, S. (2011). Dropouts and diplomas: The divergence in collegiate outcomes. In E. Hanushek, S. Machin, \& L. Woessmann (Eds.), Handbook of the economics of education (Vol. 4, pp. 573-613). Amsterdam: Elsevier. https://doi.org/10.1016/ B978-0-444-53444-6.00008-0

Brandstätter, V., \& Schüler, J. (2013). Action crisis and cost-benefit thinking: A cognitive analysis of a goal-disengagement phase. Journal of Experimental Social Psychology, 49(3), 543-553. https://doi.org/10.1016/j.jesp.2012.10.004.

Brandstätter, H., Grillich, L., \& Farthofer, A. (2006). Prognose des Studienabbruchs. [Prognosis of study dropout]. Zeitschrift für Entwicklungspsychologie und pädagogische Psychologie, 38(3), 121-131. https://doi.org/10.1026/0049-8637.38.3.121.

Brandstätter, V., Herrmann, M., \& Schüler, J. (2013). The struggle of giving up personal goals: Affective, physiological, and cognitive consequences of an action crisis. Personality and Social Psychology Bulletin, 39(12), 1668-1682. https://doi.org/10.1177/01461 67213500151.

Braxton, J. M., Sullivan, A. V., \& Johnson, R. M. (1997). Appraising Tinto's theory of college student departure. In J. C. Smart (Ed.), Higher education research: Handbook of theory and research (pp. 107-164). New York: Agathon Press.

Bryk, A. S., \& Raudenbush, S. W. (1987). Application of hierarchical linear models to assessing change. Psychological Bulletin, 101(1), 147-158. https://doi.org/10.1037/0033-2909.101.1.147.

Cabrera, A. F., Nora, A., \& Castaneda, M. B. (1993). College persistence: Structural equations modeling test of an integrated model 
of student retention. The journal of Higher Education, 64(2), 123-139. https://doi.org/10.1080/00221546.1993.11778419.

Carver, C. S., \& Scheier, M. F. (1990). Origins and functions of positive and negative affect: A control-process view. Psychological review, 97(1), 19-35. https://doi. org/10.1037/0033-295X.97.1.19.

Chemers, M. M., Hu, L. T., \& Garcia, B. F. (2001). Academic selfefficacy and first year college student performance and adjustment. Journal of Educational Psychology, 93(1), 55-64. https:// doi.org/10.1037//0022-0663.93.1.55.

Cohen, J. (1988). Statistical power analysis for the social sciences (2nd ed.). Hillsdale, NJ: Lawrence Earlbaum.

Cohen, P., West, S. G., \& Aiken, L. S. (2014). Applied multiple regression/correlation analysis for the behavioral sciences. New York: Psychology Press.

Csikszentmihalyi, M., \& Larson, R. (2014). Validity and reliability of the experience-sampling method. In M. Csikszentmihalyi (Ed.), Flow and the foundations of positive psychology (pp. 35-54). Dordrecht: Springer.

Dewberry, C., \& Jackson, D. J. (2018). An application of the theory of planned behavior to student retention. Journal of Vocational Behavior, 107, 100-110. https://doi.org/10.1016/j. jvb.2018.03.005

Dietrich, J., Viljaranta, J., Moeller, J., \& Kracke, B. (2017). Situational expectancies and task values: Associations with students' effort. Learning and Instruction, 47, 53-64. https://doi. org/10.1016/j.learninstruc.2016.10.009.

Dresel, M., \& Grassinger, R. (2013). Changes in achievement motivation among University Freshmen. Journal of Education and Training Studies, 1(2), 159-173. https://doi.org/10.11114/jets. v1i2.147.

Duque, L. C. (2014). A framework for analysing higher education performance: students' satisfaction, perceived learning outcomes, and dropout intentions. Total Quality Management \& Business Excellence, 25(1-2), 1-21. https://doi. org/10.1080/14783363.2013.807677.

Durik, A. M., Vida, M., \& Eccles, J. S. (2006). Task values and ability beliefs as predictors of high school literacy choices: A developmental analysis. Journal of Educational Psychology, 98(2), 382-393. https://doi.org/10.1037/0022-0663.98.2.382.

Durkheim, E. (1951). Suicide: A study in sociology (2nd ed.). London: Routlege.

Eccles, J. S. (2005). Subjective task value and the Eccles et al. model of achievement-related choices. In A. J. Elliot \& C. S. Dweck (Eds.), Handbook of competence and motivation (pp. 105-121). New York: Guilford Publications.

Eccles, J. S., Adler, T. F., Futterman, R., Goff, S. B., Kaczala, C. M., Meece, J. L., et al. (1983). Expectancies, values, and academic behaviors. In J. T. Spence (Ed.), Achievement and achievement motivation (pp. 75-146). San Francisco: W. H. Freeman.

Enders, C. K. (2010). Applied missing data analysis. New York: Guilford Press.

Enders, C. K., \& Tofighi, D. (2007). Centering predictor variables in cross-sectional multilevel models: A new look at an old issue. Psychological Methods, 12(2), 121-138. https://doi. org/10.1037/1082-989X.12.2.121.

Fisher, A. J., Medaglia, J. D., \& Jeronimus, B. F. (2018). Lack of group-to-individual generalizability is a threat to human subjects research. Proceedings of the National Academy of Sciences, 115(27), 106-115. https://doi.org/10.1073/pnas.17119 78115.

Flake, J. K., Barron, K. E., Hulleman, C., McCoach, B. D., \& Welsh, M. E. (2015). Measuring cost: The forgotten component of expectancy-value theory. Contemporary Educational Psychology, 41, 232-244. https://doi.org/10.1016/j.cedps ych.2015.03.002.
Fleischer, J., Leutner, D., Brand, M., Fischer, H., Lang, M., Schmiemann, P., \& Sumfleth, E. (2019). Vorhersage des Studienabbruchs in naturwissenschaftlich-technischen Studiengängen. Zeitschrift für Erziehungswissenschaft, 22(5), 1077-1097.

Freedman, D. A. (1999). Ecological inference and the ecological fallacy. International Encyclopedia of the Social \& Behavioral Sciences, 6(4027-4030), 1-7.

Gaspard, H., Dicke, A. L., Flunger, B., Schreier, B., Häfner, I., Trautwein, U., et al. (2015). More value through greater differentiation: Gender differences in value beliefs about math. Journal of Educational Psychology, 107(3), 663-677. https://doi. org/10.1037/edu0000003.

Gaspard, H., Häfner, I., Parrisius, C., Trautwein, U., \& Nagengast, B. (2017). Assessing task values in five subjects during secondary school: Measurement structure and mean level differences across grade level, gender, and academic subject. Contemporary Educational Psychology, 48, 67-84. https://doi.org/10.1016/j.cedps ych.2016.09.003.

Ghassemi, M., Bernecker, K., Herrmann, M., \& Brandstätter, V. (2017). The process of disengagement from personal goals: Reciprocal influences between the experience of action crisis and appraisals of goal desirability and attainability. Personality and Social Psychology Bulletin, 43, 524-537. https://doi.org/10.1177/01461 67216689052.

Goldstein, H. (1987). Multilevel models in education and social research. Oxford: Oxford University Press.

Gollwitzer, P. M. (1990). Action phases and mind-sets. In E. Higgins \& R. Sorrentino (Eds.), Handbook of motivation and cognition: Foundations of social behavior (Vol. 2, pp. 53-92). New York: Guilford Press.

Grassinger, R. (2018). Nicht erfüllte Erfolgserwartungen sowie nicht erfüllte Studienwerte und ihre Bedeutung für die Veränderung der Lern- und Leistungsmotivation, das emotionale Erleben und die Intention zum Studienabbruch im ersten Semester. [Unfulfilled expectancies for success, unfulfilled study values and their relevance for changes in achievement motivation, achievement emotions and the intention to drop out in the first semes-ter of a degree program]. ZeHf-Zeitschrift für empirische Hochschulforschung 2(1), 23-39. https://doi.org/10.3224/zehf.v2i1.02

Grays, M. (2013). Measuring motivation for coursework across the academic career: A longitudinal invariance study. Dissertations, 74. Harrisonburg, Virginia: James Madison University

Grunschel, C., Schwinger, M., Steinmayr, R., \& Fries, S. (2016). Effects of using motivational regulation strategies on students' academic procrastination, academic performance, and wellbeing. Learning and Individual Differences, 49, 162-170. https ://doi.org/10.1016/j.lindif.2016.06.008.

Hamaker, E. L. (2012). Why researchers should think "within-person": A paradigmatic rationale. In M. R. Mehl \& T. S. Conner (Eds.), Handbook of research methods for studying daily life (pp. 43-61). New York: The Guilford Press.

Heckhausen, J., \& Heckhausen, H. (Eds.). (2018). Motivation and action (3rd ed.). Basel, Switzerland: Springer International Publishing.

Heckhausen, H., \& Gollwitzer, P. M. (1987). Thought contents and cognitive functioning in motivational versus volitional states of mind. Motivation and Emotion, 11(2), 101-120.

Heublein, U. (2014). Student drop-out from German higher education institution. European Journal of Education, 49(4), 497-513. https://doi.org/10.1111/ejed.12097.

Heublein, U., Ebert, J., Hutzsch, C., Isleib, S., König, R., Richter, J., \& Woisch, A. (2017). Zwischen Studienerwartungen und Studienwirklichkeit: Ursachen des Studienabbruchs, beruflicher Verbleib der Studienabbrecherinnen und Studienabbrecher und Entwicklung der Studienabbruchquote an deutschen Hochschulen. [Between study expectations and the reality of studies: causes of 
study dropout, career paths of dropouts and the development of the drop-out rate at German universities]. Deutsches Zentrum für Hochschul- und Wissenschaftsforschung (DZHW), Hannover

Hosoya, G., Koch, T., \& Eid, M. (2014). Längsschnittdaten und Mehrebenenanalyse. [Longitudinal Data and Multilevel Analysis]. Kölner Zeitschrift für Soziologie und Sozialpsychologie (Sonderheft). https://doi.org/10.1007/s11577-014-0262-9.

Hovdhaugen, E. (2009). Transfer and dropout: Different forms of student departure in Norway. Studies in Higher Education, 34(1), 1-17. https://doi.org/10.1080/03075070802457009.

Jacobs, J. E., Lanza, S., Osgood, D. W., Eccles, J. S., \& Wigfield, A. (2002). Changes in children's self-competence and values: Gender and domain differences across grades one through twelve. Child development, 73(2), 509-527. https://doi. org/10.1111/1467-8624.00421.

Jiang, Y., Rosenzweig, E. Q., \& Gaspard, H. (2018). An expectancyvalue-cost approach in predicting adolescent students' academic motivation and achievement. Contemporary Educational Psychology, 54, 139-152. https://doi.org/10.1016/j.cedps ych.2018.06.005.

Kosovich, J. J., Hulleman, C. S., Barron, K. E., \& Getty, S. (2015). A practical measure of student motivation: Establishing validity evidence for the expectancy-value-cost scale in middle school. The Journal of Early Adolescence, 35(5-6), 790-816. https://doi. org/10.1177/0272431614556890.

Kosovich, J. J., Flake, J. K., \& Hulleman, C. S. (2017). Short-term motivation trajectories: A parallel process model of expectancyvalue. Contemporary Educational Psychology, 49, 130-139. https://doi.org/10.1016/j.cedpsych.2017.01.004

Kreft, I. G., \& De Leeuw, J. (1998). Introducing multilevel modeling. London: Sage.

Larsen, M. R., Sommersel, H. B., \& Larsen, M. S. (2013). Evidence on dropout phenomena at universities. (vol. 143) Copenhagen: Danish Clearinghouse for Educational Research.

Luke, D. A. (2004). Multilevel modeling. Thousand Oaks: Sage.

Luttrell, V. R., Callen, B. W., Allen, C. S., Wood, M. D., Deeds, D. G., \& Richard, D. C. (2010). The mathematics value inventory for general education students: Development and initial validation. Educational and Psychological Measurement, 70(1), 142-160. https://doi.org/10.1177/0013164409344526.

Maas, C. J., \& Hox, J. J. (2005). Sufficient sample sizes for multilevel modeling. Methodology, 1(3), 86-92. https://doi. org/10.1027/1614-2241.1.3.86.

Mashburn, A. J. (2000). A psychological process of college student dropout. Journal of College Student Retention: Research, Theory \& Practice, 2(3), 173-190. https://doi.org/10.2190/ U2QB-52J9-GHGP-6LEE.

McCrea, S. M., \& Vann, R. J. (2018). Postactional goal pursuit: Consequences of task completion for thought content, affect, and behavioral intentions. Motivation and Emotion, 42(6), 852-870. https://doi.org/10.1007/s11031-018-9713-3.

Meyer, J., Fleckenstein, J., \& Köller, O. (2019). Expectancy value interactions and academic achievement: Differential relationships with achievement measures. Contemporary Educational Psychology, 58, 58-74. https://doi.org/10.1016/j.cedpsych.2019.01.006.

Miele, D. B., \& Scholer, A. A. (2018). The role of metamotivational monitoring in motivation regulation. Educational Psychologist, 53(1), 1-21. https://doi.org/10.1080/00461520.2017.1371601.

Molenaar, P. C. (2013). On the necessity to use person-specific data analysis approaches in psychology. European Journal of Developmental Psychology, 10(1), 29-39. https://doi. org/10.1080/17405629.2012.747435.

Multon, K. D., Brown, S. D., \& Lent, R. W. (1991). Relation of selfefficacy beliefs to academic outcomes: A meta-analytic investigation. Journal of Counseling Psychology, 38(1), 30. https://doi. org/10.1037/0022-0167.38.1.30.
Multrus, F., Bargel, T., \& Ramm, M. (2005). Studiensituation und studentische Orientierungen: 9. Studierendensurvey an Universitäten und Fachhochschulen. [Study situation and student orientation: 9th student survey at universities and universities of applied sciences]. BMBF, Bonn.

Mund, M., \& Nestler, S. (2019). Beyond the cross-lagged panel model: Next-generation statistical tools for analyzing interdependencies across the life course. Advances in Life Course Research, 41, 100249. https://doi.org/10.1016/j.alcr.2018.10.002.

Musu-Gillette, L. E., Wigfield, A., Harring, J. R., \& Eccles, J. S. (2015). Trajectories of change in students' self-concepts of ability and values in math and college major choice. Educational Research and Evaluation, 21(4), 343-370. https://doi. org/10.1080/13803611.2015.1057161.

Muthén, L. K., \& Muthén, B. O. (1998-2017) Mplus User's Guide. (8th ed.) Muthén \& Muthén, Los Angeles

Nagengast, B., Trautwein, U., Kelava, A., \& Lüdtke, O. (2013). Synergistic effects of expectancy and value on homework engagement: The case for a within-person perspective. Multivariate Behavioral Research, 48(3), 428-460. https://doi.org/10.1080/00273 171.2013.775060.

Nezlek, J. B. (2011). Multilevel modeling for social and personality psychology. Los Angeles: SAGE Publications Ltd.

Nezlek, J. B., Schröder-Abé, M., \& Schütz, A. (2006). Mehrebenenanalysen in der psychologischen Forschung. [Multilevel analyses in psychological research. Advantages and potential of multilevel random coefficient modeling]. Psychologische Rundschau, 57(4), 213-223.

OECD. (2018). Education at a glance 2018. Paris: OECD Publishing. https://doi.org/10.1787/eag-2018-en

Pascarella, E. T., \& Terenzini, P. T. (1980). Predicting freshman persistence and voluntary dropout decisions from a theoretical model. The Journal of Higher Education, 51(1), 60-75. https://doi. org/10.1080/00221546.1980.11780030.

Perez, T., Cromley, J. G., \& Kaplan, A. (2014). The role of identity development, values, and costs in college STEM retention. Journal of Educational Psychology, 106(1), 315. https://doi. org/10.1037/a0034027.

Phan, H. P. (2011). Interrelations between self-efficacy and learning approaches: A developmental approach. Educational Psychology, 31(2), 225-246. https://doi.org/10.1080/01443410.2010.545050.

Raudenbush, S. W., \& Bryk, A. S. (2002). Hierarchical linear models: Applications and data analysis methods. (vol. 1) Thousand Oaks: Sage.

Richardson, M., Abraham, C., \& Bond, R. (2012). Psychological correlates of university students' academic performance: A systematic review and meta-analysis. Psychological Bulletin, 138(2), 353-387. https://doi.org/10.1037/a0026838.

Robbins, S. B., Lauver, K., Le, H., Davis, D., Langley, R., \& Carlstrom, A. (2004). Do psychosocial and study skill factors predict college outcomes? A meta-analysis. Psychological Bulletin, 130(2), 261-288. https://doi.org/10.1037/0033-2909.130.2.261.

Robinson, K. A., Perez, T., Carmel, J. H., \& Linnenbrink-Garcia, L. (2019). Science identity development trajectories in a gateway college chemistry course: Predictors and relations to achievement and STEM pursuit. Contemporary Educational Psychology, 56, 180-192. https://doi.org/10.1016/j.cedpsych.2019.01.004.

Rosenzweig, E. Q., \& Wigfield, A. (2016). STEM motivation interventions for adolescents: A promising start, but further to go. Educational Psychologist, 51(2), 146-163. https://doi. org/10.1080/00461520.2016.1154792.

Rosenzweig, E. Q., Wigfield, A., \& Hulleman, C. S. (2020). More useful or not so bad? Examining the effects of utility value and cost reduction interventions in college physics. Journal of Educational Psychology, 112(1), 166-182. https://doi.org/10.1037/ edu0000370. 
Rump, M., Esdar, W., \& Wild, E. (2017). Individual differences in the effects of academic motivation on higher education students' intention to drop out. European Journal of Higher Education, 7(4), 341-355. https://doi.org/10.1080/21568235.2017.1357481.

Schafer, J. L., \& Graham, J. W. (2002). Missing data: Our view of the state of the art. Psychological Methods, 7(2), 147-177. https:// doi.org/10.1037//1082-989X.7.2.147.

Scherrer, V., \& Preckel, F. (2019). Development of motivational variables and self-esteem during the school career: A meta-analysis of longitudinal studies. Review of Educational Research, 89(2), 211-258. https://doi.org/10.3102/0034654318819127.

Schiefele, U., Streblow, L., \& Brinkmann, J. (2007). Aussteigen oder Durchhalten. [Dropping out or persevering: What distinguishes university dropouts from other students?]. Zeitschrift für Entwicklungspsychologie und Pädagogische Psychologie, 39(3), 127-140. https://doi.org/10.1026/0049-8637.39.3.127.

Schneider, M., \& Preckel, F. (2017). Variables associated with achievement in higher education: A systematic review of meta-analyses. Psychological Bulletin, 143(6), 565. https://doi.org/10.1037/ bul0000098.

Singer, J. D., \& Willett, J. B. (2003). Applied longitudinal data analysis: Modeling change and event occurrence. Oxford: Oxford University Press.

Snijders, T. A. B. (1996). Analysis of longitudinal data using hierarchical linear models. Quality and Quantity, 30, 405-426.

Snijders, T. A. B., \& Bosker, R. J. (1999). Multilevel analysis: An introduction to basic and advanced multilevel modeling. Thousand Oaks, CA: Sage.

Sosu, E. M., \& Pheunpha, P. (2019). Trajectory of university dropout: Investigating the cumulative effect of academic vulnerability and proximity to family support. Frontiers in Education. https://doi. org/10.3389/feduc.2019.00006.

Spady, W. G. (1971). Dropouts from higher education: Toward an empirical model. Interchange, 2(3), 38-62. https://doi. org/10.1007/BF02282469.

Suhlmann, M., Sassenberg, K., Nagengast, B., \& Trautwein, U. (2018). Belonging mediates effects of student-university fit on wellbeing, motivation, and dropout intention. Social Psychology, 49, 16-28. https://doi.org/10.1027/1864-9335/a000325.

Tinto, V. (1975). Dropout from higher education: A theoretical synthesis of recent research. Review of Educational Research, 45(1), 89-125. https://doi.org/10.3102/00346543045001089.

Tinto, V. (1993). Leaving college (2nd ed.). Chicago: University of Chicago Press.
Ulriksen, L., Madsen, L. M., \& Holmegaard, H. T. (2010). What do we know about explanations for drop out/opt out among young people from STM higher education programmes? Studies in Science Education, 46(2), 209-244. https://doi.org/10.1080/03057 267.2010.504549.

UNESCO Institute for Statistics. Higher Education. Retrieved December 03, 2018, from https://uis.unesco.org/en/topic/higher-educa tion

Vancouver, J. B., \& Kendall, L. N. (2006). When self-efficacy negatively relates to motivation and performance in a learning context. Journal of Applied Psychology, 91(5), 1146-1153. https:// doi.org/10.1037/0021-9010.91.5.1146.

Vinciguerra, A., Réveillère, C., Potard, C., Lyant, B., Cornu, L., \& Courtois, R. (2019). Personality profiles of students at risk of dropping out: Resilients, overcontrollers and undercontrollers. L'Encephale, 45(2), 152-161. https://doi.org/10.1016/j.encep .2018.07.002.

Wigfield, A., \& Cambria, J. (2010). Students' achievement values, goal orientations, and interest: Definitions, development, and relations to achievement outcomes. Developmental Review, 30(1), 1-35. https://doi.org/10.1016/j.dr.2009.12.001.

Wigfield, A., Rosenzweig, E. Q., \& Eccles, J. (2017). Achievement values: Interactions, interventions, and future directions. In A. Elliot, C. Dweck, \& D. Yeager (Eds.), Handbook of competence and motivation: Theory and application (2nd ed., pp. 116-134). New York: Guilford Press.

Wooldridge, J. M. (2010). Econometric analysis of cross section and panel data. Cambridge: MIT Press.

Wrosch, C., Scheier, M. F., Carver, C. S., \& Schulz, R. (2003). The importance of goal disengagement in adaptive self-regulation: When giving up is beneficial. Self and Identity, 2(1), 1-20. https ://doi.org/10.1080/15298860309021.

Yeo, G., \& Neal, A. (2008). Subjective cognitive effort: A model of states, traits, and time. Journal of Applied Psychology, 93(3), 617. https://doi.org/10.1037/0021-9010.93.3.617.

Publisher's Note Springer Nature remains neutral with regard to jurisdictional claims in published maps and institutional affiliations. 